\title{
LA POLÉMICA ENTRE ORIENTALISTAS. (A PROPÓSITO DE BERNARD LEWIS)
}

Por

VICTOR MORALES LEZCANO

\section{ORIENTALISMO: CRISIS DE UN SABER}

Hacia 1876. Arturo de Gobineau escribía que los viajeros de Europa "van a Oriente y regresan sin ser más sabios después de su estancia en aquellos países. Ni el pasado ni el presente de aquellos parajes les es conocido; no saben ni el cómo ni el porqué de las cosas. Los paisajes que no se asemejan a los de Normandía o a los del Somersetshire no les parecen sino ridículos. Las calles de las ciudades carecen de aceras; hace mucho calor en el desierto; las abundantes ruinas son el reino de los escorpiones; las pulgas se permiten, en indiscretas cantidades, cobijarse en la persona de los visitantes; los indígenas siempre están pidiendo bakschisks, y su jerga es incomprensible» (1)

Si bien era cierto que el visitante eutopeo del mundo oriental iba desproviste de conocimientos articulados sobre las sociedades objeto de su itinerario, no menos cierto era que, desde un siglo antes de que Gobineau escribiera sus agudos relatos "asiatiques", el hemisferio occidental había generado un saber - lo que hoy denominaríamos un campo de estudio - encaminado a descifrar las lenguas, la literatura, el folklore, la arqueología y otras manifestaciones milenarias que permitieran al homo fáustico desentrañar el arcano del enigmático oriente. Aquel saber vino a llamarse Orientalismo, y tuvo sus prebostes más ilustres en William Jones, Sir Richard Burton y Edward William Lane entre los británicos; Silvestre de Sacy, Jean François Champolion, Federic Schlegel y Pascual de Gayangos entre los "continentales". Un conjunto de instituciones pertinentes y de publicaciones regulares dieron cobijo al saber orientalista de la Europa del ochocientos.

Oriente -extremo, medio y próximo; como vinieron a establecer pronto y con desconsiderada partición geométrica de las culturas todos los manuales al uso en Occidente-, también atrajo (2) las plumas más insignes del neoclasicismo y de la

(1) A. de GOBINEAO, Nouvelles Asiatiques, ed. 10/18, 1963, p. 252.

(2) Cfr. M. ROBINSON, "The Westerm Image and Western Studies of Islamн, en The Legacy of Isiam, 2. " ed., Clarendon Press, 1974, pp. 9-62. 
boga romántica europea. Goethe, Victor Hugo y Flaubert así lo testimonian; la atracción por el oriente se tradujo, entre los músicos, en fuente de inspiración inagotable desde Mozart (La Flauta Mágica, Rapto en el Serrallo) hasta Manuel de Falla (El Amor Brujo, Noches en los jardines de España) pasando por Rimsky Korsakov (Scheheresade)

Europa había sido seducida por Oriente. $Y$, además, creyó poseer las claves profuridas de su sapiencia, las reglas gobernadoras de su constitución política, a través del estudio cultivado por el Orientalismo (2).

Sin embargo, está noción de encantador encantado, de juez supremo -a la postre- - de la historia de todas las civilizaciones (noción perceptible en Occidente ya desde el Renacimiento, pero que culmina en el terreno del pensamiento critico y la filosofía de Hegel y MarX), entró en crisis a principios del siglo XX, y no ha dejado de agravarse desde entonces hasta nuestros días, coincidiendo con las dos guerras mundiales y la emancipación de los pueblos colonizados (y todo Oriente, musulmán o no, fue colonizado, a excepción de Japón y el Imperio Otomano en su núcleo turcol.

Prueba irrefutable del agravamiento de la crisis del saber orientalista son las obras de estudiosos occidentales tan destacados como Waardenburg, Rodinson, Gibb, Massignon y Lewis, a los que han unido sus voces - entre los polemistas de raigambre oriental-Laroui, Said y Al Adhm. Unos y otros, con las diferencias de grado en el tono, enfoque y conclusiones que es de rigor reconocer, han introducido planteamientos críticos que han contribuido a sacar el Orientalismo eminentemente eurocéntrico del siglo XIX, de su campana neumática, exponiéndolo al debate permanente (3). El conocido ensayo de Edward Said, publicado en 1978 en los Estados Unidos, llevó a sus últimas consecuencias polémicas el "desenmascaramiento" del Orientalismo euro-americano en cuanto saber espúreo al servicio de la dominación política (4)

La polémica está siendo salutífera, aunque escandalice a algunos miembros de la comunidad del saber, deje indiferentes a otros - y en España es notoria la indiferencia al respecto, como si se tratara de una "zarandaja"-, o se desvíe con frecuencia al terreno de la confrontación ideológica; pero, que sepamos, el saber no es siempre aséptico, y no en vano los alemanes del siglo pasado pusieron los cimientos de una disciplina dicha «sociología del conocimiento», que hoy posee una entidad incuestionable en todo el mundo.

En su Estudio de la Historia, Arnold Toynbee apuntaba que "aparte de las ilusiones debidas al éxito mundial de la Civilización Occidental en la esfera material, la falsa interpretación de la historia - comprendiendo en ella la suposición de que sólo hay una corriente de civilización, la nuestra, y de que todas las demás son tributarias a ella y se pierden en las arenas del desierto - puede asignarse a tres fuentes (las fuentes del error): la ilusión egocéntrica, la ilusión del "Oriente inmutable", y la ilusión del progreso como un movimiento que marcha en linea recta" (5).

Los decenios transcurridos desde que Toynbee redactara las consideraciones anteriores han venido a demostrar que su llamamiento al relativismo cultural era una advertencia salvadora para quien hiciera caso de los postulados que le servían de fundamento teórico. No es admisible hov, entre intelectuales y público amplio de miras,

(3) Cfr , por orden de aparición cronológico: J. J. WAARDENBURG. L'slam dans te miroir de l'Occident, Stock, 1963; 1. ABU LUGHOD, Arab Rediscovery of Europe, a Study in Cuttural Encounter, Princeton, 1963: M. RODINSON, Islam et Capitalisme, Le Seuil, 1966; H. A. R. GIBB y H. BOWEN, Islamic Society and the West, London, 1950-57; Edward SAID, Orientalism, Routledge and Kegan, 1978; S. JALAL AL-ADHM. Orientalisme et orientalisme à rebours, Beirut, 1981. Las aportaciones de M. MANZANARES de CIRRE y P. MAPTINEEZ MONTAVEZ pueden inscribirse en esta línea bibliográfica.

(4) Algunos ecos de la obra de Said, en las siguientes revistas: Bulletin of the School of Oriental and African Studies, n. ${ }^{\circ} 3$ (1979); Arabica, v, XXVII (1980); Revue d'Histoire Maghrebine (1980); The Middle East Journal, n. ${ }^{\circ} 4$ (1981); Annales, n. 3-4 (1980); Journal of Parestine Sfudies, invierno (1981); y una divulgación en España, $V$. MORALES LEZCANO, "EI Islam en la palestra occidentala, Revista de Occidente, abril $(1984)$.

(5) Cłr. A. J. TOYNBEE, Estudio de la Historia, compendio de los vs. I-VI. Emecé, 1952, pp. 53-54. 
mantener el etnocentrismo de antaño, ni creer que el progreso material lo es todo y que no conocerá techo a su crecimiento, ni podemos admitir, a la luz de la revolución china (1948), la modernización competitiva de Japón la partir de la reconstrucción de los años cincuenta) y la vitalidad (bien o mal canalizada, que ahí no vamos a entrar ahora) del mundo islámico, la noción del "oriente inmutable» con que se deleitaban les Filosophes en las academias y los contertulios de ringorrango en los salones y cafés de moda.

Ahora bien, si la literatura y la bibliografía occidentales han hecho algunos ensayos sobre el saber orientalista, que más que fortuitos obedecen a un ejercicio crítico que no ha desaparecido del todo en nuestro hemisferio, ha llegado la hora de iniciar la revisión actualizada de la Weltanschauung que poseen civilizaciones vivas con las que occidente co-existe, dialoga - más o menos amigable o airadamente-, y sobre las que ejerce (quizá desde hace siglos) no sólo dominación. sino también atractivo. La obra que pasamos a comentar es un espécimen ilustrativo de esta suerte de ensayos.

\section{II COMO EL ISLAM HA DESCUBIERTO EUROPA}

Bernard Lewis es demasiado conocido entre arabistas y orientalistas españoles como para trazar aquí una semblanza de su formación académica y de su curriculum en Gran Bretaña, Oriente musulmán y, últimamente, en destacados centros de investigación estadounidense, como Princeton (6).

Lewis es autor de un buen número de monografías y artículos en los que la erudición filtrada es siempre bien servida por una prosa ajustada. Puede decirse, sin temor a exagerar, que parecía haber llegado a la cima de su competencia, después de haber conocido tanto el reconocimiento como la hostilidad en los medios orientalistas y. fuera de ellos, en la comunidad del saber en general, y, muy en particular, en el terreno de la polémica político-ideológica.

Hace escasamente dos años, Lewis ha dado a luz otro libro: The Muslim Discovery of Europe (7). Muy pronto, la obra ha sido traducida y ha tenido justificado eco en las cajas de resonancia crítica que poseen las sociedades cultas (8).

La obra de Lewis, en cuestión, tiene antecedentes en toda su trayectoria bibliográfica anterior. Dejando aparte su clásico estudio, The Emergence of Modern Turkey 12. "edición, en Oxford University Press, que data de 1968), Lewis habia apuntado, ya hace casi treinta años, a la tesis central que recorre este último fruto de su esfuerzo. A saber: «marcados por el imponente peso militar del Imperio Otomano, los pueblos de obediencia religiosa islámica continuaron entusiasmados, hasta principios del siglo XIX, - como lo estamos actualmente nosotros, pueblos de Occidentecon la convicción de la superioridad inconmensurable e inmutable de su propia civilización con respecto de las demás. Para el musulmán del medievo, desde Andalucía hasta Persia, la Europa cristiana era un pozo oscuro de barbarie e incredulidad del cual poco tenía que temer $-v$ mucho menos, aprender - el mundo luminoso del Islam. Era un punto de vista que podía estar justificado en una época; hacia el final de la Edad Media aquella óptica era peligrosamente obsoleta" (9).

Y en otro artículo antiguo, Lewis elabora su tesis, referida puntualmente al Impe-

(6) S. S. NYANG y S. ABED-RABBO, "Bernard Lewis and islamic Studies: an Assesment", The Search. Journal for Arab and Islamic Studies, v. 5, invierno (1984), pp. 1-24.

(7) Editado por W.W. Norton and Company, en Nueva York, 1982. Hay traduccion al francess, ed. La Decouverte, 1984.

(8) Hemos localizado, por lo pronto, las siguientes ecos: M. RODINSON, en Turcica, t. XV (1983): P. KEMP, Esprit, mayojunio (1983) y X. JACOB, "Chistianity as seen by the the Turks" (B'ham. Selly Dak College, Research Papers, junio, 1984).

(9) Cfr. Bernad LEWIS, "The Muslim Discovery of Europen, en Bulletin of the School of Oriental and African Studies, V. XX (1957), pp. 409-16. 
rio Otomano en cuanto «guardián» del Islam a partir del siglo XV: «fundamentalmente, el Imperio Otomano permaneció o revertió a la forma de Estado medieval, con una mentalidad y economía medievales, pero con el peso añadido de una burocracia y de un ejército en pie de guerra que no tuvo que mantener ningún Estado medieval. En un mundo de Estados que se modernizaban rápidamente, tenía muy pocas oportunidades de sobrevivir" (10).

Una vez recordadas con dos referencias concretas la génesis de la tesis central de esta última obra del autor que se comenta, pasemos, sucintamente, a ver la articulación interna de la monografía.

Desde un principio, Lewis centra su atención en la Weltanschauung que prevaleció en el Imperio Otomano, desde el siglo XV hasta los primeros decenios del XIX - vísperas, pues, del período de la historia turco-otomana denominado Tanzimat, o de las reformas - en lo que respecta al conocimiento e inventario de su sabiduría acumulada sobre otras civilizaciones, y muy en particular sobre la Europa cristiana, es decir, los «Francos». Nutre el autor su obra, no sólo de sus antiguas investigaciores en los archivos de Estambul (Haricive, o Asuntos Exteriores; Topkapi, o Palacio del Sultán), sino también de una lectura minuciosa de autores clásicos en las fuentes de la historiografía otomana (Kâtip Çelebi, Mehmed Said Efendi, Azmi Efendi), a los que va sacando partido para conducir el discurso de la monografía al final conclusivo.

Según Lewis - y estas líneas no son sino una apurada reducción de los doce capítulos de la obra - el poder. "Cesareo-papista" en Estambul, desde la consolidación de la dinastía otomana, pasando por la edad dorada de Solimán el Magnífico (1520-66) hasta, aproximadamente, el reinado de Selim III (1797-1807), no mantuvo suficientemente alerta el dispositivo diplomático, científico, lingǘstico y técnico que - fuera del terreno bélico- le permitiera sostener un pulso airoso, va que no una victoria, con el ecumene cristiano (por no hablar del reino persa, antagónico suyo también, no obstante su pertenencia al (slam)

¿Por qué esa indiferencia y complejo de superioridad frente a los infieles (Kâfir) de Europa? ¿Cómo explicar congruentemente el etnocentrismo otomano-islámico, por extensión? Porque aunque Lewis reconoce que, en muchas ocasiones, la curiosidad de un viajero orienta!, la perspicacia de un embajador (caso de los plenipotenciarios del reino de Marruecos cerca de la Corte española de los Borbones en el siglo XVIIII, la iniciativa de algún visir $y$, sobre todo, de ciertos oficiales del poderoso ejército otomano, aconsejaron el estudio y seguimiento del modo de funcionamiento de los gobiernos occidentales, la incorporación de sus técnicas y artes industriales y militares, en suma, el progreso paulatino de su civilización, por antagónica que fuera, todo ello no bastó para que la sugerencia adquiriera estado de necesidad y se emprendieran las reformas que, a finales del siglo XVII, eran de urgencia.

Estos cuestionamientos, que están en los orígenes de la encuesta de Lewis y sirven de locomotiva a su lectura y articulación de las fuentes que utiliza, le llevan a concluir que no fue sino la autocomplacencia (11) que inspira el poder legitimado por la religión, lo que explica la incapacidad otomana para acoplar a la construcción de su Imperio las innovaciones de los tiempos modernos: secularización creciente de las comunidades cristianas, progreso irreversible de las técnicas, control de las vías de comunicación marítimas, curiosidad intelectual tanto por la Antigüedad clásica como por las "otras civilizaciones" existentes en el universo-mundo. La tradición cristalizada en la ldjtihâd musulmana habría puesto, según él, un formidable dique a la modernización del Imperio, le habría paralizado la circulación en sus arterias, mien-

(10) Cfr. LEWIS, "Some Reflections on the Decline of the Ottoman Empiren, Studia Islamica, V. IX (1958), pp. 111-27. Otra comtribución pertinente es su "Politics and War", en The Legacy of Islam, ed. cit., pp. 156-209.

(11) Cfr. todo el capítulo aLes raisons d'une méconnaissance», pp. 281-94 de la edición francesa de la obra de Lewis. 
tras que el ecumene europeo habría iniciado, precisamente desde el "otoño de la Edad Median, una dialéctica inversa a la del mundo islámico durante los siglos de administración otomana.

No siendo orientalistas de profesión, ni mucho menos turcólogos, hagamos un alto en el camino para recuperar, en síntesis selectiva, los análisis que otras ciencias sociales han hecho del Imperio Otomano y de las causas que condujeron a tan vasto y poderoso Estado a la crisis de sus instituciones y a la agonía de supervivencia en que "encalló" (todos recordamos que de ser tratado como un enemigo temible por las Cancillerías europeas del siglo XVI, e incluso, XVII, pasó a ser tipificado como el uhombre enfermo" del sistema internacional que se configura a partir del Congreso de Viena en 18151.

\section{III \\ LAS CAUSAS DE LA DECADENCIA DEL IMPERIO TURCO-OTOMANO, CONTRASTADAS}

Dejemos en el rincón polvoriento en que han caído merecidamente, no las explicaciones, sino las estigmatizaciones fáciles del Imperio - «brutalidad de sus hordas". "fanatismo de sus jenízaros", "voluptuosidad y depravación de sus élites", y un breve etcétera - para fijar la atención en algunas opiniones autorizadas en la materia.

En su famoso capítulo, "Los Tipos de Dominación". Max Weber describió la de tipo tradicional, y dentro de ésta caracterizó a la de naturaleza patrimonial. "Con la aparición de un cuadro administrativo (y militar) personal del señor, toda dominación tradicional tiende al patrimonialismo y en el caso extremo de poder de mando al sultanatom (12).

Las corrientes sociológicas posteriores a Weber abundan en su línea de procedimiento. Así, S. N. Eisenstadt, y más recientemente C. V. Findley, han parado mientes en el fenómeno de las "sociedades burocráticas históricas" (Imperio Chino, Absolutismo europeo, Persia sasánida, Antiguo Egipto, etc.), dentro de las cuales procede incorporar al imperio Turco-Otomano como forma política. Según esta escuela sociológica, el peso de la burocracia militar y civil al servicio del Poder legitimador del Sultanato (¿despotismo oriental?), terminaron por provocar tanto la asfixia del aparato de gobierno, como la rebelión en las provincias y el malestar social generalizado (13). Los osmanlíes serian, según Toynbee, un ejemplo canónico de "civilización detenida". incapaz de superar los límites de sus posibilidades por mor de sus trabas internas y del bloque de potencias que le fueron antagónicas.

No menos cierto es que el seguimiento de la historia moderna del Imperio TurcoOtomano revela la pervivencia de una difusa preocupación, por parte de algunos miembros de sus élites más preclaras, en lo que atañía al buen funcionamiento administrativo, la cohesión interna y el rechazo eficaz del permanente asedio a sus dilatadas fronteras. Esta preocupación, en cualquier caso, sólo tuvo un eco amplio a partir de la segunda mitad del siglo XIX, y muy dramáticamente a lo largo del reinado de Abdulhamid II (1876-1909); es en ese fin de siglo cuando, de una parte, se intenta capitalizar el factor religioso a través del movimiento panislámico en cuanto cordón umbilical que impida la desintegración imperial, mientras que, de otra parte, se recurre a lo que la historiografía más reciente ha designado como "modernización defensiva"

(12) Max WEBER, Economia y Sociedad, Fondo de Cultura Económica, 1964, v. I, pp. 185.

(13) Aparte la obra de WITTFOGEL, cfr. S. N. EISENSTADT, Los sistemas politicos de los Imperios. Ascension y caida de las sociedades burocraticas históricas, Rev. de Occidente, 1966, y C. V. FINDLEY, Bureaucratic Reform in the Ottcman Empire. The Sublime Porte, 1789-1922, Princeton University Press, 1980, pp. $255 \mathrm{~cm}$. 
ante la hegemonía ubicua del Occidente industrializado (14). Jugando con el beneficio de la perspectiva, podemos aseverar cómodamente hoy que nadie ni nada podia salvar al imperio de su fatal desmoronamiento en la primera guerra mundial. No menos evidente es que en la posguerra, los grupos progresistas y occidentalófilos combinaron amor a la patria turca y modernización decidida bajo la república paternalista de Kemal Atatürk (1923-38)

- Fieles a la observación de Marx en Das Kapital (15), los historiadores marxistas hacen hincapié en el hecho de la burocracia estatal otomana en cuanto aglutinante de la atomizada estructura del Imperio ("sistema patrimonial redistributivo"). Sin embargo, este sistema se revelará incapaz de sobrevivir cómodamente, en la medida en que las transformaciones en la economía de trueque internacional hicieron cada vez más perentoria la subsistencia financiera del Estado Otomano, del orden social antiguo leclipse de la vieja nobleza militar de los sipahis, insurrecciones de los pachas en las provincias, y creciente confiscación del comercio exterior del imperio por los "factores" de Occidente establecidos en Levantel. El Estado Otomano, concluye esta línea de orientación historiográfica, era burocrático, agrario y periférico - se sobreentiende que con respecto al gran comercio y a las rutas del Atlántico de los siglos XVI. XVIII (16); a pesar de su supervivencia, no tenía rescate posible, no obstante los esfuerzos liberales del periodô Tanzimat $y$ de la función aperturista - y discretamente secularizadora - que jugó el movimiento joven turco antes de 1914.

A la luz de la selectiva recapitulación de autoridades que hemos practicado, ien qué medida coinciden las conclusiones de la monografía de Lewis con los análisis realizados por otros estudiosos - fuera del campo del orientalismo - sobre la naturaleza del Imperio Turco-Otomano, y la cuestión, aqui palpitante, de si su decadencia fue función de uno (Islam) o varios factores concomitantes?

Es cierto que el Estado islámico estuvo basado, al menos hasta el siglo XIX, en los principios de realeza (mulk) y tradición coránica (hadith), facilitadores de la trayectoria humana en la tierra para acceder al paraiso (shari'a) (17). El Estado Otomano fue una variante de aquél, y en cuanto tal estuvo inspirado en los principios del Islam clásico; fue, hasta cierto grado, un Estado de fuerte cobertura ideológica islámica

Ahora bien, atribuir a la monolítica confesionalidad de aquel Estado Isiempre respetuoso con las minorías religiosas) la causa de su decadencia $-y$, por tanto, pasar un veredicto negativo sobre la cosmovisión musulmana que inspiró a los hombres y pueblos del Imperio Otomano parece ser una profunda convicción de Lewis, muy arraigada en él - como se ha visto desde hace algunos decenios -- y perteneciente al terreno de las creencias, ricamente ilustrada y documentada en su caso, pero no por ello menos perteneciente al dominio de las creencias, en el sentido que Ortega confería al término ( las ideas se tienen, en las creencias se está»).

(14) Cfr. a este respecto. las ponencias de K. H. KARPAT, «Pan-Islamism: Imperial Plat or Muslim Popular Resistance to Imperialism", Y Osman OKYAR, "The Role of the State in the Economy of the Ottoman Empire during the XIX the Century", sendas ponencias a los Congresos IV y V del Comité para el Estudio de las Sociedades Pre-otomana y Otomana, celebra. dos en Cuenca (1981) y Túnez (1982). A ambos estudiosos queremos expresarles nuestro agradecimiento por el estimulo de su aportación.

15) Marx crevó haber descubierto en el aimpuesto sobre los bienes raices el secreto de la autoconservación del Imperio Otomanow: "wenn adrerseits die Naturalform der Grundrente, in Asien zugleich das Hauptelement der Staatssteuer, dort auf Produktionsverhältnissen beruht, welche sich mit der Unwandelbarkeit von Naturverhältnissen reproduzieren, erhält jene Zahłunsform rückwirkend die alte Produktionsform. Sie bildet eines der Selbsterhaltungsgeneimnisse des türkischen Reichs". Cfr. Das Kapital, Verlarg Ulmstein, 2. ed, 1969, p. 113.

(16) Cfr. Halil INALCIK, "The Ottoman Economic Mind and Aspects of the Ottoman Economym, en Studies in the Economic History of the Middle East from the Rise of Islam to the present day, Oxford University Press, 1970; e IIkay SUNAR, "Anthropologie politique et economique: I'Empire Ottoman et sa transformation", en Annales, mayo-agosto 119801 , pp. $551-779$.

117) Cfr. Albert HOURANI, Arabic Thought in the Liberal Age, Oxford University Press, 1962, p. 1 v sgtes. (uThe Isiamic State", "The Ottoman Empiren. 
También perecieron, luego de una prolongada agonia, los imperios ruso y austrohúngaro, en 1917-19, y ninguno de los dos eran teocracias musulmanas; lo que, sin embargo, parece desprenderse del repaso efectuado a otras opiniones autorizadas, es que la legitimación del poder del sultán (califa de la Umma islámica) por la religión, aseguró la reproducción secular de una burocracia civil y militar a su servicio en Estambul y en las lejanas provincias europeas y árabes del Imperio. Esa burocracia, administradora de las rentas generadas por una sociedad y un sistema productivo eminentemente agro-pastoril, condujo al Estado Otomano a una situación de bloqueo, no sólo por la autocomplacencia y etnocentrismo en que cae, tarde o pronto, toda élite poderosa, sino por el cariz anacrónico que, a partir del siglo XVII, adquirió crecientemente el conjunto del Imperio, en medio de un universo de Estados europeos en trance de consolidarse, interna e internacionalmente, como potencias de primer rango militares y mercantiles. La salida de aquel laberinto de anacronismo no fue posible, a lo que parece, tanto por motivos internos a la estructura del sistema otomano como por motivos externos - y aquí el asedio de los "Francos" de Europa no es una expresión-comodín, sino una recurrente actuación hostigadora que va desde los siglos de las Cruzadas hasta que el destino del "hombre enfermo de Occidente» se ventiló en las Cancillerías y en el servicio de la deuda exterior y de los empréstitos de la banca europea.

La obra de Lewis, que historiográficamente lleva a conclusiones interesantemente coincidentes con las de otros científicos sociales, pone, sin embargo, un énfasis que - aunque contenido - no deja de resultar reiterativo, cuando apunta a las limitaciones etnocéntricas inherentes a la cosmovisión del Islam, y a la estrecha causalidad que ve entre la autocomplacencia otomana y el anacronismo social, cultural y tecnológico en que se hundió la última forma de Estado islámico que logró reunir bajo el manto de su discutida administración a una considerable extensión de la comunidad musulmana.

El fenómeno de la autocomplacencia y endurecimiento arterial de algunos Imperios y sociedades, su incapacidad final para salir airosos del reto de los cambios y de las amenazas cursadas desde el exterior por otras potencias, no nos parece satisfactoriamente explicable por la vía que privilegia Lewis en su obra (el peso - el fardodel Islam), sino que exige un esfuerzo de comprensión pluricausal (de raigambre socio-económica) sin el que ensayos de este género, por mucha erudición que desplieguen, corren el riesgo de mutilar la complejidad - siempre molesta - de la realidad histórica. 